\title{
Capital accumulation with and without land market liberalization: beyond the "Win-Win" situation
}

\author{
George Vachadze
}

\section{Correspondence:}

george.vachadze@csi.cuny.edu Department of Political Science, Economics, and Philosophy, College of Staten Island and Graduate Center, City University of New York, 2800 Victory Blvd, Staten Island, NY 10314, USA

\section{Springer}

\begin{abstract}
This paper examines the effect of land market liberalization on the dynamics of capital accumulation. It is shown that the land market liberalization, which is accompanied with the transfer of agricultural technology, may not always offer a "win-win" outcome for developed and developing countries. Improved agricultural productivity generates a growth enhancing externality. However, land market liberalization affects the balance between the equalizing force of the diminishing returns technology and the un-equalizing force of the low income elasticity of the agricultural commodity demand. As a result, land market liberalization accompanied with the transfer of agricultural productivity, may not always guarantee a "win-win" outcome for developed and developing countries. If improvement of agricultural productivity is insignificant then land market liberalization can cause "win-lose" situation for developed and developing countries. This result suggests that one should be very careful in a policy proposal designed to foster the process of development through foreign land ownership. It is important to recognize that apart from benefits, foreign land ownership also creates a disadvantage for capital accumulation and causes the magnification of the world income inequality.
\end{abstract}

JEL classification: F43, O11, R14

Keywords: Dynamics of capital accumulation, Land market liberalization, Transfer of agricultural technology

\section{Background}

Food prices, which almost doubled between 2006 and 2008, had a major impact on the perception of food insecurity. Rising food prices hit hard to the balance of payments of many food importing countries. In order to insure themselves, those countries started to acquire farmland under their control. Reports from the International Food Policy Research Institute (IFPRI) estimate that during the last decade tens of millions of acres of farmland has been acquired by countries where the consumption of agricultural commodities far exceeds the production (see Von Braun and Meinzen-Dick (16) for more details). Food-importing countries with land and water constraints but rich in oil resources, such as the Gulf States, or countries with large populations and food security concerns, such as China, Japan, India, and South Korea, are seeking opportunities to produce food and biofuel crops overseas (see Borras et al. (3) for more details).

(C) 2013 Vachadze; licensee Springer. This is an Open Access article distributed under the terms of the Creative Commons

Attribution License (http://creativecommons.org/licenses/by/2.0), which permits unrestricted use, distribution, and reproduction in any medium, provided the original work is properly cited. 
Land acquisitions are occurring mainly in developing countries like Brazil, Cambodia, Indonesia, Laos, Madagascar, Pakistan, Philippines, Uganda, Sudan and others, where production costs are relatively low and where land and water resources are more abundant than in the investor nation (see Vidal (15), Cotula et al. (5), and Allen (1), for more details).

Many powerful international institutions, such as The World Bank, the European Bank for Reconstruction and Development, and the US Millennium Challenge Corporation, are actively advising national governments in developing countries to allow a large-scale acquisition of domestic land by foreigner investors (see Li (11) and World Bank (17) among others). These international institutions argue that a large-scale land acquisition is a way to reduce poverty through transfer of technology and technical know-how from developed to developing countries and improve the overall efficiency in the agricultural sector in general. While the robust empirical evidence about the impact of foreign land ownership on economic growth is lacking, many developing countries have already simplified their land ownership laws for foreign firms and governments. ${ }^{a}$ The speed of land acquisition has provoked opposition from farmers' organizations, human rights groups, and other social movements as they raise concerns that foreign land ownership can have a negative impact on poor local people, who risk losing access to and control over the land on which they depend too much. ${ }^{\mathrm{b}}$ In addition, unrestricted foreign land ownership could cause a spike in property prices so that citizens of the low and middle class are never able to afford land again. ${ }^{\mathrm{c}}$

In the present paper, I take a small step toward reconciling two conflicting views about land market liberalization: one is a "win-win" view, typically encouraged by the World Bank and the UN Food and Agriculture Organization, and the other "win-lose" (win for rich and lose for poor) view, usually supported by numerous non-profit organizations such as La Via Campesina, the Oakland Institute, GRAIN, Food First, and many others (See for example Nierenberg and Pollack (13)). To this end, I analyze a general equilibrium model within which I can investigate the effects of land market liberalization on the dynamics of capital accumulation and on the well-being of a nation. The world economy consists of identical countries that differ in their levels of agricultural sector productivity and the initial capital stock. The model is set up in such a way that, in the absence of land market liberalization, a country with a relatively more productive agricultural sector converges monotonically to a unique steady state and achieves higher capital stock, higher wage income, higher consumption, and higher welfare in general. ${ }^{d}$ This result can be tempting to conclude that poor countries will benefit from the land market liberalization if such liberalization comes with the transfer of more efficient agricultural technology. In this paper I demonstrate that, as a result of land market liberalization, the unique steady state can lose its stability property and two asymptotically stable steady states come in existence. The unique steady state can become unstable because, with the integrated land markets, the land price in different countries must move together. This creates a disadvantage for relatively poor countries because of low income elasticity of agricultural demand. The land market will crowd out domestic investment in capital and will create a negative spillover for next generations. That is to say, a low aggregate investment in capital lowers the income of the next generations of the same country, creating a downward spiral of low-income/low-investment in capital. The opposite force will operate in a relatively rich country which because of land market liberalization will face relatively low land prices. 
This will create an upward spiral of high-income/high-investment in capital. As a result, a "win-win" outcome is not necessarily guaranteed through the land market liberalization even if such liberalization comes with the improvement of agricultural sector productivity in the relatively poor country.

The paper is organized as follows. Section The model introduces the model with a simple, analytically tractable structure, which is capable of capturing the effect of the land market integration on the dynamics of capital accumulation. Section The autarky case demonstrates the existence and uniqueness of an interior steady state and show its stability property under rational expectations dynamics. Section Two country model considers the world economy in which foreign land ownership is allowed and the productivity of agricultural sector is equalized. In such a set-up, I show that the foreign land ownership right can cause the long-run divergence of otherwise symmetric economies. Section Conclusions summarizes results and concludes.

\section{Methods}

\section{The model}

Let us consider an infinite-horizon, a standard neoclassical overlapping generations model, modified only to include a land market. ${ }^{e}$ The world economy consists of two countries: Country 1 and Country 2. Countries are identical in all respect except for their levels of productivity in the agricultural sector and the initial capital stock. ${ }^{\mathrm{f}}$ In each period there are two generations alive: young and old. Population size of each generation is constant and normalized to unity. Agents supply one unit of labor while young and consume while old. A single manufacturing commodity is produced by an infinitely lived neoclassical firm which combines two factors of production, capital and labor.

The produced final commodity is usable for consumption and for investment. Per capita output in country $i=1,2$, in period $t$, is $y_{i t}=f\left(k_{i t}\right)$, where $k_{i t}$ denotes the capital per worker in Country $i$ and $f: \mathbb{R}_{+} \rightarrow \mathbb{R}_{+}$is the production function in intensive form. We assume that the production function satisfies the standard neoclassical properties: $f$ is twice continuously differentiable on $\mathbb{R}_{++}$; continuous, strictly increasing, and strictly concave, on $\mathbb{R}_{+}$; and satisfies the following boundary conditions, $f(0)=0, \lim _{k \downarrow 0} f^{\prime}(k)=\infty$, and $\lim _{k \uparrow \infty} f^{\prime}(k)=0$. Factor markets are competitive and factor rewards are determined according to the marginal product rule, i.e., at time $t$, the wage rate and the rate of return on one unit of capital are given by $W(k):=f(k)-k f^{\prime}(k)$ and $f^{\prime}(k)$ respectively. Existing capital depreciates fully within a period.

After receiving the wage income $W\left(k_{i t}\right)$, young agents decide how much to invest in capital and how much land to purchase in the competitive land market. Aggregate supply of land in each country is fixed and normalized to unity. Productivity of land $A_{i}>0$ in each country is constant over time and is treated as an exogenous parameter. Purchase of $x_{i t}$ units of land implies the consumption of $A_{i} x_{i t}$ units of agricultural commodity. After harvesting the agricultural commodity, land ownership can be sold in order to increase the consumption of the manufacturing commodity. ${ }^{\mathrm{g}}$

Purchasing $x_{i t}$ units of land at price $p_{i t}$ implies the following choice of investment in capital $W\left(k_{i t}\right)-x_{i t} p_{i t}$, where $x_{i t} p_{i t}$ is the spending on the land market. Since the rate of return on capital is $f^{\prime}\left(k_{i t+1}\right)$, it follows that the old agent's consumption bundle is $\left(c_{i t+1}, A_{i} x_{i t}\right)$, where $c_{i t+1}=\left[W\left(k_{i t}\right)-x_{i t} p_{i t}\right] f^{\prime}\left(k_{i t+1}\right)+x_{i t} p_{i t+1}$. Thus the land market serves two purposes: First, land can be used as an investment vehicle, because it is durable 
and consumers can re-sell it in the next period in order to increase their consumption of manufacturing commodity. Second, land can be used as a consumption commodity, because land owners harvest the agricultural commodity from which they derive utility. Young agents choose the optimal levels of land/investment in capital by maximizing the following utility function $\left(c_{i t+1}, x_{i t}\right) \mapsto \ln c_{i t+1}+u\left(A_{i} x_{i t}\right)$, where $u$ is a twice continuously differentiable on $\mathbb{R}_{++}$; continuous, strictly increasing, and strictly concave on $\mathbb{R}_{+}$; and satisfies the following boundary condition, $\lim _{x \downarrow 0} u^{\prime}(x)=\infty$.

Young agents take the pair of current - $\left(k_{i t}, p_{i t}\right)$, and next period - $\left(k_{i t+1}, p_{i t+1}\right)$, capital stock and land price as given and maximize the following lifetime utility

$$
\ln \left\{\left[W\left(k_{i t}\right)-x_{i t} p_{i t}\right] f^{\prime}\left(k_{i t+1}\right)+x_{i t} p_{i t+1}\right\}+u\left(A_{i} x_{i t}\right),
$$

by choosing an optimal land holding, $x_{i t}$. The first order condition implies that

(a) If $p_{i t} f^{\prime}\left(k_{i t+1}\right)>p_{i t+1}$, then the optimal level of land holding, $x_{i t}$, satisfies ${ }^{\mathrm{h}}$

$$
\frac{p_{i t} f^{\prime}\left(k_{i t+1}\right)-p_{i t+1}}{\left[W\left(k_{i t}\right)-x_{i t} p_{i t}\right] f^{\prime}\left(k_{i t+1}\right)+x_{i t} p_{i t+1}}=A_{i} u^{\prime}\left(A_{i} x_{i t}\right) .
$$

(b) If $p_{i t} f^{\prime}\left(k_{i t+1}\right) \leq p_{i t+1}$, then it is optimal for young agents to invest all their wage income into a land purchase and thus the optimal level of land holding is

$$
x_{i t}=\frac{W\left(k_{i t}\right)}{p_{i t}} .
$$

\section{The autarky case}

First let us consider the case of autarky, when all markets operate only domestically, foreign land ownership is not allowed, and price of land is determined domestically. A simple demographic structure of the consumption sector implies that young agents are net demanders, while old agents are net suppliers of land. Since all markets operate only domestically and the aggregate supply of land is constant and normalized to unity, it follows that $x_{i t}=1$, for all $t$. This, with the assumptions of no first period consumption and full depreciation of capital, implies that the capital stock in the next period is

$$
k_{i t+1}=W\left(k_{i t}\right)-p_{i t} .
$$

Suppose $p_{i t} f^{\prime}\left(k_{i t+1}\right) \leq p_{i t+1}$, then $x_{i t}=1$ implies that $p_{i t}=W\left(k_{i t}\right)$ and thus $k_{i t+1}=0$. This implies a contradiction with $p_{i t} f^{\prime}\left(k_{i t+1}\right) \leq p_{i t+1}$ because $\lim _{k_{i t+1} \downarrow} f^{\prime}\left(k_{i t+1}\right)=\infty$. Suppose $p_{i t} f^{\prime}\left(k_{i t+1}\right)>p_{i t+1}$, then $x_{i t}=1$ with (2) implies that

$$
p_{i t+1}=\left(p_{i t}-U\left(A_{i}\right) W\left(k_{i t}\right)\right) f^{\prime}\left(k_{i t+1}\right) \text { where } U\left(A_{i}\right):=\frac{A_{i} u^{\prime}\left(A_{i}\right)}{1+A_{i} u^{\prime}\left(A_{i}\right)} .
$$

Equations (4) and (5) together imply that the evolution of $\left(k_{i t}, p_{i t}\right)$ in a closed economy under perfect-foresight dynamics is described by the following time one map $M^{i}(.,$.$) :$ $\mathbb{R}_{+}^{2} \rightarrow \mathbb{R}_{+}^{2}$,

$$
\left(\begin{array}{c}
k_{i t+1} \\
p_{i t+1}
\end{array}\right)=M^{i}\left(k_{i t}, p_{i t}\right)=\left(\begin{array}{l}
m_{1}\left(k_{i t}, p_{i t}\right) \\
m_{2}^{i}\left(k_{i t}, p_{i t}\right)
\end{array}\right),
$$

where

$$
m_{1}(k, p):=W(k)-p \text { and } m_{2}^{i}(k, p):=\left(p-U\left(A_{i}\right) W(k)\right) f^{\prime}\left[m_{1}(k, p)\right] .
$$


(6) and (7) imply that the steady state pair $\left(k_{i}^{*}, p_{i}^{*}\right)$ satisfies the following system of equations

$$
p_{i}=W\left(k_{i}\right)-k_{i} \text { and } p_{i}=U\left(A_{i}\right) \frac{W\left(k_{i}\right) f^{\prime}\left(k_{i}\right)}{f^{\prime}\left(k_{i}\right)-1} .
$$

After eliminating the steady state price of land, $p_{i}$, from the above system and then rearranging terms, we obtain that the steady state capital, $k_{i}^{*}$, should solve the following equation

$$
\Psi\left(k_{i}\right)=U\left(A_{i}\right) \text { where } \Psi(k):=\left(1-\frac{k}{W(k)}\right)\left(1-\frac{1}{f^{\prime}(k)}\right) .
$$

In order to simplify the analysis and focus on the situation when there is a unique steady state in a closed economy, we make the following assumption.

Assumption 1. Suppose that the production and utility functions satisfy

(a) $k \mapsto \frac{k}{W(k)}$ is strictly increasing on $\mathbb{R}_{++}$and $\lim _{k \downarrow 0} \frac{k}{W(k)}=0$;

(b) $x \mapsto x u^{\prime}(x)$ is strictly decreasing on $\mathbb{R}_{++}$;

Assumption 1.(a), can be interpreted as a restriction on the elasticity of substitution between capital and labor inputs. In particular, Assumption 1.(a) is equivalent to $\sigma(k)>$ $\alpha(k)$, where

$$
\sigma(k):=\frac{W(k) f^{\prime}(k)}{W^{\prime}(k) f(k)} \text { and } \alpha(k):=\frac{k f^{\prime}(k)}{f(k)}
$$

denote the elasticity of substitution between capital and labor inputs and capital share in production respectively. Justification for Assumption 1.(a) is based on empirical observations made on the one hand by Klump et al. (10), and Chirinko (4) who report that the elasticity of substitution between capital and labor inputs is between 0.5 and 1 and on the other hand by Gollin (7) who reports that capital share in production is between 0.32 to 0.40 .

Assumption 1.(b), can be interpreted as a restriction on the income elasticity of demand for the agricultural commodity. In particular, Assumption 1.(b) implies that the income elasticity of demand for the agricultural commodity is less than one. ${ }^{\mathrm{i}}$ Justification for low income elasticity is based on the empirical observation of Engel's law made by Crafts (6), Matsuyama (12), and Piyabha et al. (14).

Let us define a constant

$$
\widehat{k}:=\min \left\{k \in \mathbb{R}_{++} \mid \Psi(k)=0\right\} .
$$

One can easily verify that if assumption 1 .(a) is satisfied then (a) $k \mapsto \Psi(k)$ is strictly decreasing and positive on the interval $(0, \widehat{k})$, and (b) $\Psi$ satisfies the following boundary conditions $\lim _{k \downarrow 0} \Psi(k)=1$ and $\Psi(\widehat{k})=1$. At the same time, if assumption 1.(b) is satisfied then $A \mapsto U(A)$ is strictly decreasing and $U(A) \in(0,1)$ for any $A \in(0, \infty)$.

Proposition 1. If Assumption 1 is satisfied then (a) there exists a unique and interior steady state in a closed economy, $\left(K^{*}\left(A_{1}\right), K^{*}\left(A_{2}\right)\right)$; and (b) for any initial capital stocks, $\left(k_{10}, k_{20}\right)>0$, there exists a unique saddle path along which the economy converges monotonically to $\left(K^{*}\left(A_{1}\right), K^{*}\left(A_{2}\right)\right)$. 
Proof of the above Proposition can be found in Appendix. The above proposition implies that, under autarky, there exists a unique and interior steady state to which the world economy converges monotonically along the unique saddle path. Convergence happens for any initial distribution of capital stock, $\left(k_{10}, k_{20}\right)$. Under Assumption 1 , the model predicts that the economy with more efficient agricultural productivity accumulated more capital ${ }^{j}$ and achieves higher steady state welfare. ${ }^{k}$ This result can be tempting to conclude that poor countries will benefit from foreign land ownership if such ownership comes with the transfer of more efficient agricultural technology.

\section{Two country model}

The positive link between agricultural productivity and capital accumulation demonstrated above crucially depends on the closed economy assumption. To see this, consider a world economy in which the foreign land ownership is allowed. Suppose the ownership right comes with the transfer of agricultural productivity. Let efficiency in the agricultural sector, in both countries, be described by the same parameter $A$ (we can assume without loss of generality that $A=A_{2}>A_{1}$ ). On the one hand, capital accumulation in each country implies the following equations to hold ${ }^{\mathrm{m}}$

$$
k_{1 t+1}=W\left(k_{1 t}\right)-x_{1 t} p_{t} \text { and } k_{2 t+1}=W\left(k_{2 t}\right)-x_{2 t} p_{t} .
$$

On the other hand, it follows from agents' optimization and from the equalization of land prices that

$$
p_{t+1}=\left(p_{t}-\frac{U\left(A x_{i t}\right)}{x_{i t}} W\left(k_{i t}\right)\right) f^{\prime}\left(k_{i t+1}\right)
$$

to hold for $i=1,2$. (12) and (13) with land market clearing condition $x_{1 t}+x_{2 t}=2$ implies that $x_{1 t}=X\left(k_{1 t}, k_{2 t}, p_{t}\right)$ should solve the following equation

$$
\frac{f^{\prime}\left[W\left(k_{1 t}\right)-x_{1 t} p_{t}\right]}{f^{\prime}\left[W\left(k_{2 t}\right)-\left(2-x_{1 t}\right) p_{t}\right]}=\frac{p_{t}-\frac{U\left(A\left(2-x_{1 t}\right)\right)}{2-x_{1 t}} W\left(k_{2 t}\right)}{p_{t}-\frac{U\left(A x_{1 t}\right)}{x_{1 t}} W\left(k_{1 t}\right)} .
$$

(12), (13), and (14) together implies that the evolution of the world economy under the perfect foresight dynamics is described by the following time one map

$$
\left(\begin{array}{l}
k_{1 t+1} \\
k_{2 t+1} \\
p_{t+1}
\end{array}\right)=N\left(k_{1 t}, k_{2 t}, p_{t}\right)=\left(\begin{array}{l}
n_{1}\left(k_{1 t}, k_{2 t}, p_{t}\right) \\
n_{2}\left(k_{1 t}, k_{2 t}, p_{t}\right) \\
n_{3}\left(k_{1 t}, k_{2 t}, p_{t}\right)
\end{array}\right),
$$

where $n_{1}, n_{2}$, and $n_{3}$ are given by

$$
\begin{aligned}
& n_{1}\left(k_{1}, k_{2}, p\right):=W\left(k_{1}\right)-X\left(k_{1}, k_{2}, p\right) p \\
& n_{2}\left(k_{1}, k_{2}, p\right):=W\left(k_{2}\right)-\left(2-X\left(k_{1}, k_{2}, p\right)\right) p \\
& n_{3}\left(k_{1}, k_{2}, p\right):=\left(p-\frac{U\left(A X\left(k_{1}, k_{2}, p\right)\right)}{X\left(k_{1}, k_{2}, p\right)} W\left(k_{1}\right)\right) f^{\prime}\left[n_{1}\left(k_{1}, k_{2}, p\right)\right] .
\end{aligned}
$$

Steady state analysis of the closed economy implies the existence of two symmetric steady states $(0,0)$ and $\left(K^{*}(A), K^{*}(A)\right)$ (in which both countries hold equal amounts of capital and incomes are equalized) and two asymmetric steady states $\left(0, K^{*}(2 A)\right)$ and $\left(K^{*}(2 A), 0\right)$ (in which one country holds positive amount of capital, while the other deteriorates to zero level of capital). In order to investigate the existence of additional steady states, in which both countries hold positive but different levels of capital, we refine Assumption 1. 
Assumption 2. Suppose production and utility functions are:

(a) $f(k)=k^{\alpha}$, where the parameter $\alpha \in(0,1)$ describes the capital share in production;

(b) $u(x)=\frac{x^{1-\gamma}-1}{1-\gamma}$, where the parameter $\gamma \in(1, \infty)$ describes the income elasticity of demand on agricultural commodity;

One can easily verify that Assumption 2 is fully compatible with Assumption 1. Thus, results obtained in Section The autarky case remains. It follows from (12), (13), and (14), that for a given steady state distribution of land holding $(x, 2-x)$, the steady state capital pair $\left(k_{1}, k_{2}\right)$ solves the following system of equations

$$
\Psi\left(k_{1}\right)=U(A x) \text { and } \Psi\left(k_{2}\right)=U(A(2-x)) .
$$

It follows from Assumption 2 and from expression (11) that $\widehat{k}=\min \left\{\alpha^{\frac{1}{1-\alpha}},(1-\alpha)^{\frac{1}{1-\alpha}}\right\}$ and the distribution of the steady state capital stocks in the world economy is given by $k_{1}=K^{*}(A x)$ and $k_{2}=K^{*}(A(2-x))$, where

$$
K^{*}(y):=\left(\frac{1}{2}-\sqrt{\frac{1}{4}-\frac{\alpha(1-\alpha)}{1+y^{1-\gamma}}}\right)^{\frac{1}{1-\alpha}} \in(0, \widehat{k}) .
$$

Price equalization implies that the steady state land holding in the home country, $x$, should satisfy the following equation $\Delta(x, A)=0$, where $\Delta:(0,2) \times \mathbb{R}_{+} \rightarrow \mathbb{R}$ and $P^{*}: \mathbb{R}_{++} \rightarrow \mathbb{R}$ are defined as

$$
\Delta(x, A):=P^{*}(A x)-P^{*}(A(2-x)) \text { and } P^{*}(y)=A \frac{U(y)}{y} \frac{W\left(K^{*}(y)\right) f^{\prime}\left(K^{*}(y)\right)}{f^{\prime}\left(K^{*}(y)\right)-1} .
$$

Proposition 2. If $\alpha \gamma>1$ then $\left.\frac{\partial \Delta(x, A)}{\partial x}\right|_{x=1}=0$ has a unique solution at $A=A^{c}(\gamma)$, where $A^{c}$ is a strictly increasing function and satisfies the following boundary conditions

$$
A^{c}\left(\frac{1}{\alpha}\right)=0 \text { and } \lim _{\gamma \uparrow \infty} A^{c}(\gamma)=1 \text {. }
$$

(a) If either $\alpha \gamma \leq 1$ or $\alpha \gamma>1$ and $A \leq A^{c}(\gamma)$ then there exists a unique and symmetric steady state in the world economy $\left(K^{*}(A), K^{*}(A)\right)$, which is globally stable.

(b) If $\alpha \gamma>1$ and $A>A^{c}(\gamma)$ then there exists three interior steady states with land holdings $\left(x_{L}(A), x_{H}(A)\right),(1,1)$, and $\left(x_{H}(A), x_{L}(A)\right)$, where $x_{L}(A)=2-x_{H}(A) \in(0,1)$ solves $\Delta(x, A)=0$. Symmetric steady state $\left(K^{*}(A), K^{*}(A)\right)$ is unstable, while two asymmetric steady states

$$
\left(K^{*}\left[A x_{L}(A)\right], K^{*}\left[A x_{H}(A)\right]\right) \text { and }\left(K^{*}\left[A x_{H}(A)\right], K^{*}\left[A x_{L}(A)\right]\right)
$$

are asymptotically stable.

The above Proposition implies that the parameter space $(\gamma, A) \in(1, \infty) \times(0, \infty)$ can be divided into two regions (see Figure 1). When either $\alpha \gamma \leq 1$ or $\alpha \gamma>1$ and $A \leq A^{c}(\gamma)$ then the world economy converges to a symmetric steady state and thus the relatively poor country with an inefficient agricultural sector will benefit from the land market liberalization in the long run, while the relatively rich country with more efficient agricultural sector will neither lose nor benefit from the land market liberalization. 


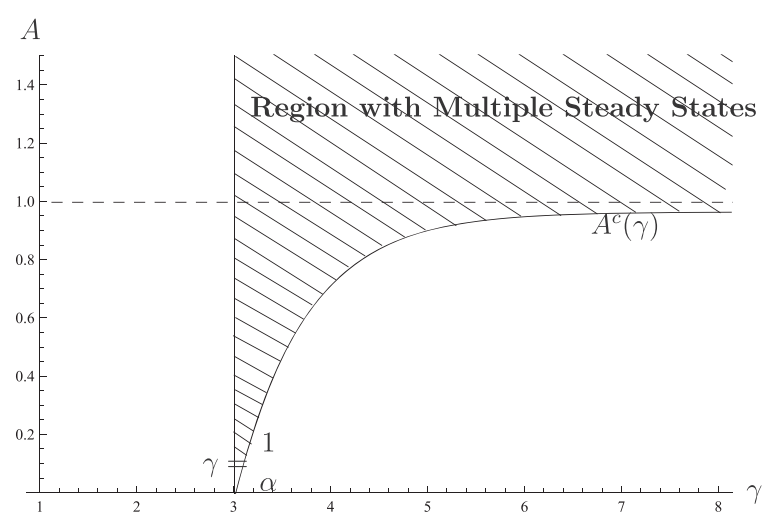

Figure 1 Parameter regions with unique and multiple interior steady states.

If $\alpha \gamma>1$ and $A>A^{c}(\gamma)$ then the unique and symmetric steady state is unstable and two asymptotically stable steady states

$$
\left(K^{*}\left[A x_{L}(A)\right], K^{*}\left[A x_{H}(A)\right]\right) \text { and }\left(K^{*}\left[A x_{H}(A)\right], K^{*}\left[A x_{L}(A)\right]\right)
$$

exist as only possible long-run outcomes in the world economy. The possibility for the existence of two asymmetric and interior steady states is shown in Figure 2. In such a situation, a country with a relatively inefficient agricultural sector can either benefit or lose from the land market liberalization. The long-run outcome depends on the relative levels of the agricultural productivity and the capital stock at the time of land market liberalization. In order to demonstrate the situation when a country finds itself in a disadvantage situation due to a land market liberalization, we consider the case when $\alpha \gamma>1$ and $A=A_{2}>A^{c}(\gamma)$. Suppose $A_{1} \in(0, A)$, then the world economy under autarky will converge to the steady state $\left(K^{*}\left(A_{1}\right), K^{*}(A)\right)$, where $0<K^{*}\left(A_{1}\right)<K^{*}(A)$. Suppose the relatively poor country liberalizes the land market and the transfer of agricultural technology from rich to poor country occurs. Then the world economy will converge to the steady state in which the distribution of land holdings is $\left(x_{1}, x_{2}\right)=\left(x_{L}(A), x_{H}(A)\right)$, and the distribution of capital is $\left(K^{*}\left[A x_{L}(A)\right], K^{*}\left[A x_{H}(A)\right]\right)$. It is clear that the home country will find itself in a disadvantaged situation ${ }^{\mathrm{n}}$ due to the land market liberalization if $A_{1} \in\left(A x_{L}(A), A\right)$ and will benefit from the land market liberalization if $A_{1} \in\left(0, A x_{L}(A)\right)$. This is visualized in Figure 3.

The main results obtained in the paper can be summarized by Figure 4. If either $\alpha \gamma \leq 1$ or $\alpha \gamma>1$ and the productivity of the agricultural sector in the relatively rich country is sufficiently low, $A \leq A^{c}(\gamma)$, then the world economy will converge to a symmetric steady

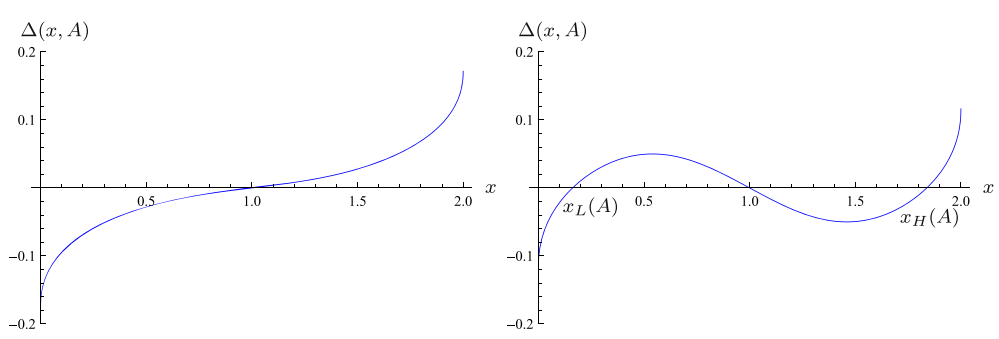

Figure $2 \alpha \gamma>\mathbf{1}$. (a) Unique steady state, $A<A^{c}(\gamma)(\mathbf{b})$ Multiple steady states, $A>A^{c}(\gamma)$. 


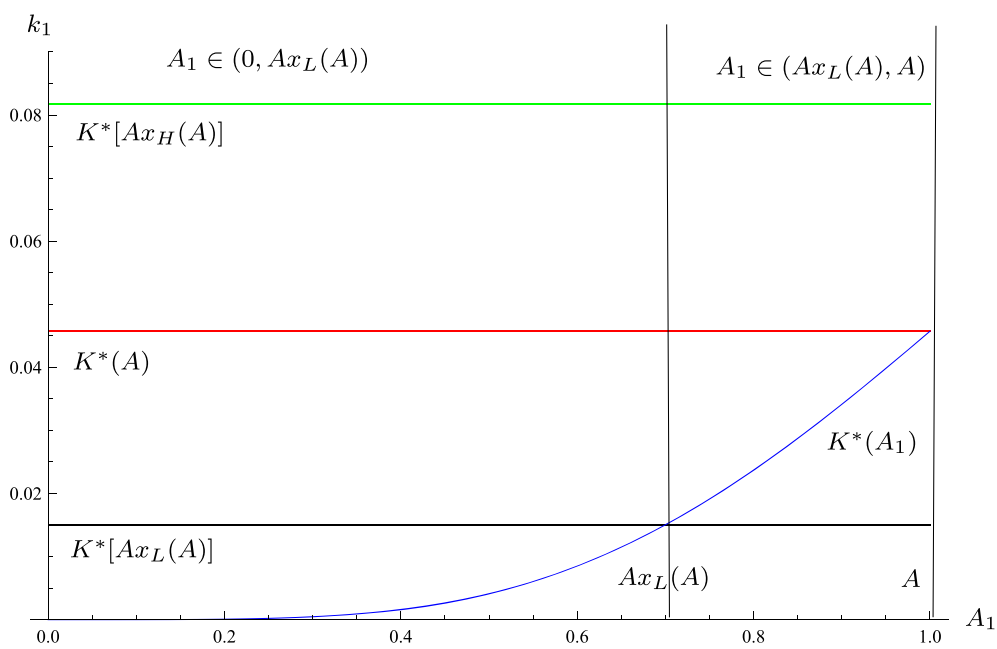

Figure $3 \boldsymbol{\alpha} \boldsymbol{\gamma}>\mathbf{1}$ and $\boldsymbol{A}>\boldsymbol{A}^{\boldsymbol{c}}(\boldsymbol{\gamma})$. If $A_{1} \in\left(0, A x_{L}(A)\right)$ then the home country benefits from the land market liberalization; If $A_{1} \in\left(A x_{L}(A), A\right)$ then the home country finds itself in a disadvantage situation due to the land market liberalization.

state $\left(K^{*}(A), K^{*}(A)\right)$ due to the land market liberalization. As a result, in the long run, only the relatively poor country benefits from the liberalization process, while the relatively rich country will sustain the same level of capital, income, and welfare in the long run (see region $\mathcal{N} \mathcal{W}$, no-lose/win region, on Figure 4). If $\alpha \gamma>1$ and the productivity of the agricultural sector is sufficiently high, $A>A^{c}(\gamma)$, then the world economy will be divided into relatively rich and relatively poor countries even when the productivity across countries is the same. Whether the land market liberalization helps or hurts the process of capital accumulation and the long-run welfare depends on the relative strength of the productivity improvement in the home country. In particular, if the productivity of the agricultural sector in the home country is sufficiently low, $A_{1}<A x_{L}(A)$, then both countries will benefit from the land market liberalization, because $0<K^{*}\left(A_{1}\right)<K^{*}\left[A x_{L}(A)\right]$

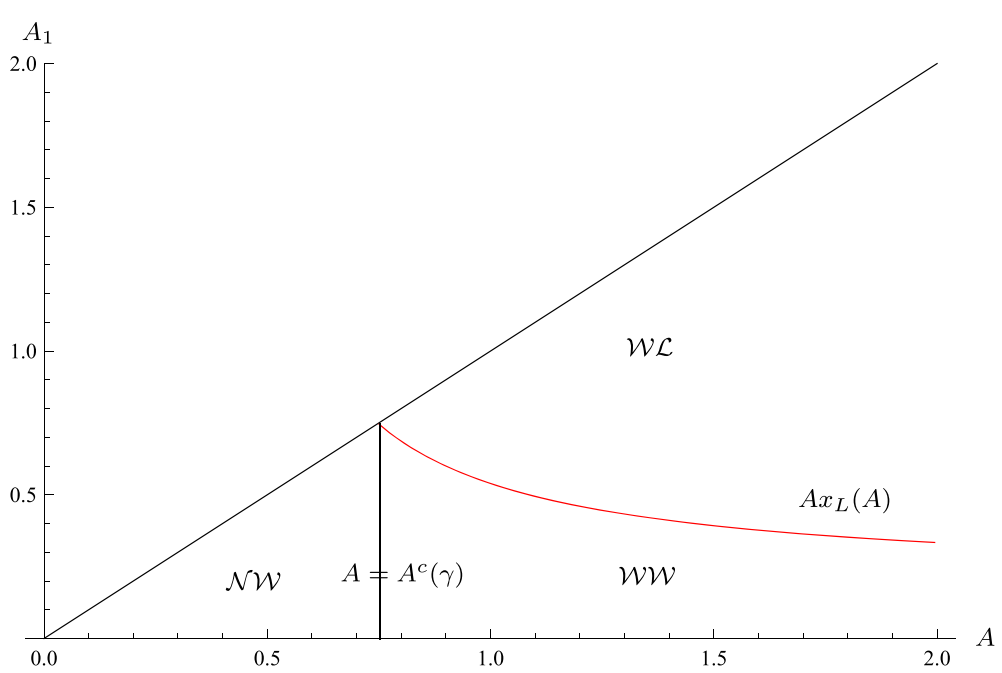

Figure $4 \alpha \gamma>1$ and $A=A_{2}>A_{1} ;$ Parameter regions when the relatively rich/poor country benefits/loses from the land market liberalization. $\mathcal{N} \mathcal{W}, \mathcal{W} \mathcal{W}$, and $\mathcal{W} \mathcal{L}$, refer to "no-lose/win", "win/win", and "win/lose" situations respectively. 
and $0<K^{*}(A)<K^{*}\left(A x_{H}(A)\right)$ (see region $\mathcal{W W}$, win-win region, on Figure 4). In contrast, if the productivity of the agricultural sector in the home country is sufficiently high, $A_{1}>A x_{L}(A)$, then the home country will suffer while the foreign country will benefit from the land market liberalization because $K^{*}\left(A_{1}\right)>K^{*}\left[A x_{L}(A)\right]$ and $0<K^{*}(A)<$ $K^{*}\left[A x_{H}(A)\right]$ (see region $\mathcal{W} \mathcal{L}$, win-lose region, on Figure 4).

\section{Results and discussion}

The main goal of this paper was to analyze the effects of land market liberalization and the transfer of agricultural technology on the dynamics of capital accumulation and on long run welfare. The main results of the paper suggests that a policy maker should be careful to use only positive feedback mechanisms that the foreign land ownership can create for economic development, because in reality, several different links co-exist between the foreign land ownership right and the long run economic development. That is why an important lesson learned from this study is to be careful in any policy intervention; a clear goal to speed up the process of development can indeed push the country even deeper into an underdevelopment trap.

\section{Conclusions}

The paper considered a model of the world economy consisting of structurally identical economies and analyzed the stability of a unique symmetric steady state with and without foreign land ownership rights. This does not imply that initial differences in production technology, consumer preferences, or land endowment are unimportant for the world economy not to converge to the symmetric steady state. Instead, I demonstrated that even a small amount of inequality, expressed in terms of initial capital stock, can be magnified after foreign land ownership is allowed. I do not argue that foreign land ownership should be blamed for non-convergence and other sources of inequality such as geography, credit market imperfections, lack of transparency in corporate governance, and poorly designed public policies, are unimportant sources for non-convergence. Instead, I demonstrated that the foreign land ownership alone can create advantage/disadvantage for initially rich/poor countries and halt the process of convergence.

The model was setup in such a way that the world economy in autarky converges to a unique steady state, which is globally stable under rational expectations. In such steady state, a country with a more productive agricultural sector accumulates more capital. Introduction of foreign land ownership rights puts a relatively rich/poor country in a advantageous/disadvantageous situation and creates an upward/downward spiral of high/low wage income, and high/low investment in domestic physical capital. The argument of the paper can be used to dispute the claim made in the World Bank annual report that a large-scale foreign land acquisition is a way to reduce poverty (see World Bank (17)). Instead, I argue that a large-scale foreign land acquisition in some cases can create a "win-win" for rich investors and a "lose-lose" outcome for poor, land selling countries.

\section{Appendix}

Lemma 1. Let the agent's utility be given by $(c, x) \mapsto \log c+u(A x)$. If $x \mapsto x u^{\prime}(x)$ is strictly decreasing then the income elasticity of agricultural commodity demand is less than unity. 
Proof. Let $w$ and $p$ denote current wage and land price, and let $r_{1}$ and $p_{1}$ denote next period rate of return on capital and next period land price. Then it follows (2) that demand of agricultural commodity satisfies the following equation

$$
\frac{x(w, p)}{U(A x(w, p))}=\frac{r_{1}}{p r_{1}-p_{1}} w .
$$

This implies that

$$
\frac{d \ln x(w, p)}{d \ln w}=\frac{1}{1-\frac{A x(w, p) U^{\prime}(A x(w, p))}{U(A x(w, p))}},
$$

where

$$
\frac{y U^{\prime}(y)}{U(y)}=\left(1+\frac{y u^{\prime \prime}(y)}{u^{\prime}(y)}\right) \frac{1}{1+y u^{\prime}(y)} .
$$

$y \mapsto y u^{\prime}(y)$ is strictly decreasing (see Assumption 1) if and only if $\frac{y u^{\prime \prime}(y)}{u^{\prime}(y)}<-1$. This with (25) implies that $\frac{y U^{\prime}(y)}{U(y)}<0$, which with (24) implies that $\frac{d \ln x(w, p)}{d \ln w} \in(0,1)$.

\section{Proof of Proposition 1}

(a) An interior steady state of the closed economy $i$ is a stationary pair $\left(k_{i}^{*}, p_{i}^{*}\right)$ which solves (9). ${ }^{\circ}$ The existence and uniqueness of the interior steady state $K^{*}\left(A_{i}\right)$ follows from (9) and from the following properties of $\Psi: \Psi$ is strictly decreasing, $\Psi(\widehat{k})=0$, and $\lim _{k \downarrow 0} \Psi(k)=1$.

(b) In order to understand the dynamics of the economy, I evaluate the Jacobian matrix of time one map at the unique and interior steady state $k_{i}^{*}=K^{*}\left(A_{i}\right)$. (4) and (5) imply that

$$
m_{11}\left(k_{i}^{*}, p_{i}^{*}\right)=W^{\prime}\left(k_{i}^{*}\right) \text { and } m_{12}\left(k_{i}^{*}, p_{i}^{*}\right)=-1,
$$

and

$$
\begin{gathered}
m_{21}^{i}\left(k_{i}^{*}, p_{i}^{*}\right)=p_{i}^{*} W^{\prime}\left(k_{i}^{*}\right)\left(\frac{f^{\prime \prime}\left(k_{i}^{*}\right)}{f^{\prime}\left(k_{i}^{*}\right)}-\frac{f^{\prime}\left(k_{i}^{*}\right)-1}{W\left(k_{i}^{*}\right)}\right) \\
m_{22}^{i}\left(k_{i}^{*}, p_{i}^{*}\right)=-p_{i}^{*} \frac{f^{\prime \prime}\left(k_{i}^{*}\right)}{f^{\prime}\left(k_{i}^{*}\right)}+f^{\prime}\left(k_{i}^{*}\right) .
\end{gathered}
$$

(26) and (27) together imply that the trace and determinant of the Jacobian matrix at the interior steady state are:

$$
T_{i}^{*}=\frac{W^{\prime}\left(k_{i}^{*}\right)}{f^{\prime}\left(k_{i}^{*}\right)} \frac{f\left(k_{i}^{*}\right)-k_{i}^{*}}{k_{i}^{*}}+f^{\prime}\left(k_{i}^{*}\right) \text { and } D_{i}^{*}=W^{\prime}\left(k_{i}^{*}\right) \frac{f\left(k_{i}^{*}\right)-k_{i}^{*}}{W\left(k_{i}^{*}\right)} .
$$

Since $f^{\prime}\left(k_{i}^{*}\right)>1$ and $W^{\prime}>0$, it follows from (28) that $T_{i}^{*}>0$ and $D_{i}^{*}>0$. In addition,

$1-T_{i}^{*}+D_{i}^{*}=1-f^{\prime}\left(k_{i}^{*}\right)+f^{\prime \prime}\left(k_{i}^{*}\right) W\left(k_{i}^{*}\right)+f^{\prime}\left(k_{i}^{*}\right) W^{\prime}\left(k_{i}^{*}\right)=W\left(k_{i}^{*}\right) f^{\prime}\left(k_{i}^{*}\right) \Psi^{\prime}\left(k_{i}^{*}\right)<0$,

because $\Psi^{\prime}\left(k_{i}^{*}\right)<0$. (29) with $T_{i}^{*}>0$ and $D_{i}^{*}>0$ implies that a unique and interior steady state is a saddle. Local properties of the interior steady state implies the existence and uniqueness of a locally stable manifold, which is one-dimensional, continuously differentiable manifold, tangential to the linear space spanned by the eigenvector of the Jacobian matrix with eigenvalue less than one. Global properties of the dynamical system given in equation (4) can be established via the application of the Stable Manifold Theorem (see Hartman (9) 
and Guckenheimer and Holmes (8) for more details). Global invertibility of the time one map with uniqueness of an interior steady state implies the existence and global uniqueness of a perfect-foresight equilibrium which can be obtained through the backward iteration of the locally stable manifold. Existence of the globally stable manifold implies that for any $k_{i 0}$ there exists a unique $p_{i 0}$ such that the pair $\left(k_{i 0}, p_{i 0}\right)$ is on the globally stable manifold. The economy converges to steady state equilibrium monotonically along the stable manifold. For any values other than $p_{i 0}$, the economy steps on diverging path which is inconsistent with the perfect foresight equilibrium. The same argument is used in (Böhm V, Kikuchi T, Vachadze G: Natural resources and patterns of overtaking, Unpublished).

Lemma 2. Let us define a function $Z:[0, \widehat{z}] \rightarrow \mathbb{R}$, where $\widehat{z}:=\min \{\alpha, 1-\alpha\}$, as follows

$$
Z(z):=\frac{\gamma-1}{\alpha(1-\alpha)^{2}} \frac{(\alpha(1-\alpha)-z)(\alpha-z)(1-z)}{1-2 z} .
$$

(a) If $\gamma \in\left(1, \frac{1}{\alpha}\right)$ then $Z(z)<1$ for $z \in[0, \widehat{z}]$;

(b) If $\gamma=\frac{1}{\alpha}$ then $Z(0)=1$ and $Z(z)<1$ for $z \in(0, \widehat{z}]$;

(c) If $\gamma \in\left(\frac{1}{\alpha}, \infty\right)$ then $Z(z)=1$ has a unique solution on the interval $(0, \widehat{z})$;

Proof. It is easy to observe that $Z(\alpha(1-\alpha))=0$ and

$$
Z(0)=\frac{\alpha(\gamma-1)}{1-\alpha} \in\left\{\begin{array}{cl}
(0,1) & \text { if } \alpha \gamma<1 \\
1 & \text { if } \alpha \gamma=1 \\
(1, \infty) & \text { if } \alpha \gamma>1
\end{array}\right.
$$

If $\alpha \in(0,0.50]$, then $\widehat{z}=\alpha, Z(\alpha)=0$, and $Z$ is strictly decreasing and positive on $(0, \alpha(1-\alpha))$. If $\alpha \in(0.50,1)$, then $\widehat{z}=1-\alpha$ and $Z(1-\alpha)=1-\gamma<0$, and $Z$ is strictly decreasing and positive on $(0, \alpha(1-\alpha))$. This implies the claim of the lemma.

Lemma 3. (a) If $\alpha \gamma<1$ then $P^{*}$ is strictly decreasing and satisfies the boundary conditions $\lim _{y \downarrow 0} P^{*}(y)=\infty$ and $\lim _{y \uparrow \infty} P^{*}(y)=0$;

(b) If $\alpha \gamma=1$ then $P^{*}$ is strictly decreasing and satisfies the boundary conditions $\lim _{y \downarrow 0} P^{*}(y)=\alpha^{\frac{2 \alpha-1}{1-\alpha}}(1-\alpha)^{\frac{\alpha}{1-\alpha}}$ and $\lim _{y \uparrow \infty} P^{*}(y)=0$;

(c) If $\alpha \gamma>1$ then there exists a unique $y^{c}$ which solves the equation

$$
\frac{\gamma-1}{\alpha(1-\alpha)^{2}} \frac{\left(\alpha(1-\alpha)-\left[K^{*}(y)\right]^{1-\alpha}\right)\left(\alpha-\left[K^{*}(y)\right]^{1-\alpha}\right)\left(1-\left[K^{*}(y)\right]^{1-\alpha}\right)}{1-2\left[K^{*}(y)\right]^{1-\alpha}}=1
$$

$P^{*}$ is strictly increasing on the interval $\left(0, y^{c}\right)$, strictly decreasing on the interval $\left(y^{c}, \infty\right)$ and satisfies the boundary conditions $\lim _{y \downarrow 0} P^{*}(y)=\lim _{y \uparrow \infty} P^{*}(y)=0$;

Proof. It follows from (18) and (19) that

$$
\frac{d K^{*}(y)}{d y} \frac{y}{K^{*}(y)}=\frac{\gamma-1}{\alpha(1-\alpha)^{2}} \frac{\left(1-\alpha-\left[K^{*}(y)\right]^{1-\alpha}(y)\right)\left(\alpha-\left[K^{*}(y)\right]^{1-\alpha}\right)\left(1-\left[K^{*}(y)\right]^{1-\alpha}\right)}{1-2\left[K^{*}(y)\right]^{1-\alpha}}
$$


and

$$
\begin{aligned}
\frac{d P^{*}(y)}{d y} \frac{y}{P^{*}(y)}= & \frac{\gamma-1}{\alpha(1-\alpha)^{2}} \frac{\left(\alpha(1-\alpha)-\left[K^{*}(y)\right]^{1-\alpha}\right)\left(\alpha-\left[K^{*}(y)\right]^{1-\alpha}\right)\left(1-\left[K^{*}(y)\right]^{1-\alpha}\right)}{1-2\left[K^{*}(y)\right]^{1-\alpha}} \\
& -1 .
\end{aligned}
$$

(34) with Lemma 2 implies the monotonicity properties of $P^{*}$. We can observe that $K^{*}$ is strictly increasing with

$$
\lim _{y \downarrow 0} K^{*}(y)=0 \text { and } \lim _{y \uparrow \infty} K^{*}(y)=\widehat{k} .
$$

(35) implies that, for any $\gamma \in(1, \infty), \lim _{y \uparrow \infty} P^{*}(y)=0$ and

$$
\lim _{y \downarrow 0} P^{*}(y)=\frac{\gamma-1}{1-\alpha}(\alpha(1-\alpha))^{\frac{\alpha}{1-\alpha}} y^{\frac{\alpha \gamma-1}{1-\alpha}}=\left\{\begin{array}{cc}
\infty & \text { if } \alpha \gamma<1 \\
\alpha^{\frac{2 \alpha-1}{1-\alpha}}(1-\alpha)^{\frac{\alpha}{1-\alpha}} \alpha & \text { if } \alpha \gamma=1 \\
0 & \text { if } \alpha \gamma>1 .
\end{array}\right.
$$

Proof of Proposition 2 Monotonicity of $A^{c}$ follows from Lemmas 3 and 2 and from expression (32). The same Lemmas also imply that (a) if $\alpha \gamma=1$ then $K^{*}\left(A^{c}(\gamma)\right)=0$ and thus $A^{c}(\gamma)=0$; and (b) if $\gamma \uparrow \infty$ then $\left[K^{*}\left(A^{c}(\gamma)\right) \uparrow \uparrow(1-\alpha)\right.$ and thus $A^{c}(\gamma) \uparrow 1$ because $U(A)$ and $K^{*}(A)$ converges pointwise to $U_{\infty}(A)$ and $K_{\infty}^{*}(A)$ respectively as $\gamma \uparrow \infty$, where

$$
U_{\infty}(A)=\left\{\begin{array}{c}
1 \quad \text { if } A<1 \\
0.50 \text { if } A=1 \\
0 \quad \text { if } A>1,
\end{array} \text { and } K_{\infty}^{*}(A)=\left\{\begin{array}{cc}
0 & \text { if } A<1 \\
K^{*}(1) & \text { if } A=1 \\
\widehat{k} & \text { if } A>1 .
\end{array}\right.\right.
$$

Steady States: It follows from Lemma 3 that if $\alpha \gamma<1$ then $\Delta(., A)$ is continuous, strictly decreasing, and satisfies the boundary conditions

$$
\lim _{x \downarrow 0} \Delta(x, A)=\infty \text { and } \lim _{x \uparrow 2} \Delta(x, A)=-\infty .
$$

This implies that $\Delta(x, A)=0$ admits a unique solution at $x=1$. If $\alpha \gamma>1$ then

$$
\lim _{x \downarrow 0} \Delta(x, A)=-P^{*}(2 A)<0 \text { and } \lim _{x \uparrow 2} \Delta(x, A)=P^{*}(2 A)>0 .
$$

This implies that $\Delta(x, A)=0$ can admits at most three solutions, $x_{L}(A) \in(0,1), x_{M}(A)=$ 1 , and $x_{H}(A)=2-x_{L}(A) \in(1,2)$. If $\alpha \gamma>1$ then it follows from Lemma 2 that

$$
\frac{\left(\alpha(1-\alpha)-\left[K^{*}(A)\right]^{1-\alpha}\right)\left(\alpha-\left[K^{*}(A)\right]^{1-\alpha}\right)\left(1-\left[K^{*}(A)\right]^{1-\alpha}\right)}{1-2\left[K^{*}(A)\right]^{1-\alpha}}=\frac{\alpha(1-\alpha)^{2}}{\gamma-1},
$$

admits a unique solution. Let $A=A^{c}(\gamma)$ denotes the solution. Lemmas 3 and 2 imply that if $A<A^{c}(\gamma)$ then $\Delta(., A)$ is increasing at $x=1$ and thus there exists a unique solution at $x=1$. In contrast, if $A>A^{c}(\gamma)$ then $\Delta(., A)$ is decreasing at $x=1$ and thus $\Delta(x, A)=0$ admits three solutions.

Stability: $\alpha \gamma>1$ and $A>A^{c}(\gamma)$ is a necessary and sufficient condition for instability of symmetric steady state.

Sufficiency: In order to show that $\alpha \gamma>1$ and $A>A^{c}(\gamma)$ is a sufficient condition for instability of symmetric steady state it is enough to show that the dynamical system (13) 
is locally unstable at $k_{1}=k_{2}=K^{*}(A)$. This is equivalent to show that at least two roots of the characteristic equation

$$
\operatorname{Det}\left(\begin{array}{ccc}
n_{11}-\lambda & n_{12} & n_{13} \\
n_{12} & n_{11}-\lambda & n_{13} \\
n_{31} & n_{31} & n_{33}-\lambda
\end{array}\right)=0,
$$

are more than unity in modulus. Characteristic roots of the Jacobian matrix solve the following equation

$$
\left(n_{11}-\lambda\right)^{2}\left(n_{33}-\lambda\right)+2 n_{12} n_{13} n_{31}-2\left(n_{11}-\lambda\right) n_{13} n_{31}-\left(n_{33}-\lambda\right) n_{12}^{2}=0 .
$$

Grouping first and fourth and second and third terms together, we obtain that the characteristic roots satisfy the following equation

$$
\left(n_{11}-n_{12}-\lambda\right)\left(n_{11}+n_{12}-\lambda\right)\left(n_{33}-\lambda\right)-2\left(n_{11}-n_{12}-\lambda\right) n_{13} n_{31}=0 .
$$

It follows from the above expression that

$$
\lambda_{1}=n_{11}-n_{12},
$$

while $\lambda_{2}$ and $\lambda_{3}$ satisfy the following quadratic equation

$$
\lambda^{2}-\lambda\left(n_{11}+n_{12}+n_{33}\right)+\left(n_{11}+n_{12}\right) n_{33}-2 n_{13} n_{31}=0 .
$$

At symmetric steady state $k_{1}=k_{2}=k^{*}, x_{1}=x_{2}=1$, and thus it follows from (14) that

$$
X_{1}\left(k^{*}, k^{*}, p^{*}\right)=-X_{2}\left(k^{*}, k^{*}, p^{*}\right)=\frac{W^{\prime}\left(k^{*}\right)}{2} \frac{\frac{f^{\prime}\left(k^{*}\right)}{W\left(k^{*}\right)}-\frac{f^{\prime \prime}\left(k^{*}\right)}{f^{\prime}\left(k^{*}\right)-1}}{f^{\prime}\left(k^{*}\right)\left(1-\frac{A U^{\prime}(A)}{U(A)}\right)-\frac{p^{*} f^{\prime \prime}\left(k^{*}\right)}{f^{\prime}\left(k^{*}\right)-1}},
$$

and $X_{3}\left(k^{*}, k^{*}, p^{*}\right)=0$. This with (17) and (44) implies that

$$
\lambda_{1}=W^{\prime}\left(k^{*}\right) \frac{\frac{k^{*}}{W\left(k^{*}\right)}-\frac{A U^{\prime}(A)}{U(A)}}{1-\frac{p^{*}}{f^{\prime}\left(k^{*}\right)} \frac{f^{\prime \prime}\left(k^{*}\right)}{f^{\prime}\left(k^{*}\right)-1}-\frac{A U^{\prime}(A)}{U(A)}},
$$

Since $-\frac{A U^{\prime}(A)}{U(A)}=(\gamma-1)(1-U(A))$ and $\Psi\left(k^{*}\right)=U(A)$, it follows from (47) that

$$
\lambda_{1}>1 \Leftrightarrow \frac{\gamma-1}{\alpha(1-\alpha)^{2}} \frac{\left(\alpha(1-\alpha)-\left[k^{*}\right]^{1-\alpha}\right)\left(\alpha-\left[k^{*}\right]^{1-\alpha}\right)\left(1-\left[k^{*}\right]^{1-\alpha}\right)}{1-2\left[k^{*}\right]^{1-\alpha}}>1 .
$$

This with (34) and with Lemmas 3 and 2 implies $\lambda_{1}>1$ if and only if $\alpha \gamma>1$ and $A>A^{c}(\gamma)$. In addition,

$$
\begin{aligned}
& \lambda_{2}+\lambda_{3}=n_{11}+n_{12}+n_{33}=W^{\prime}\left(k^{*}\right)+f^{\prime}\left(k^{*}\right)-p^{*} f^{\prime \prime}\left(k^{*}\right)>0, \\
& \lambda_{2} \lambda_{3}=\left(n_{11}+n_{12}\right) n_{33}-2 n_{13} n_{31}=W^{\prime}(k) f^{\prime}(k)>0, \\
& \left(1-\lambda_{2}\right)\left(1-\lambda_{3}\right)=1-f^{\prime}(k)+\left[W(k) f^{\prime}(k)\right]^{\prime}<0 .
\end{aligned}
$$

It follows from (49), (50), and (51), that both roots $\lambda_{2}$ and $\lambda_{3}$ are positive, real, and satisfy $0<\lambda_{2}<1<\lambda_{3}$. I.e., $\lambda_{1} \geq 1$ is a sufficient condition for local instability of the symmetric steady state $\left(k^{*}, k^{*}, p^{*}\right)$. Since there can exist at most two interior asymmetric steady states in the world economy, the local instability of the symmetric steady state should imply the long run divergence.

Necessity: In order to show that $\alpha \gamma>1$ and $A>A^{c}(\gamma)$ is a necessary condition for a long run divergence it is enough to show that whenever divergence happens then $\alpha \gamma>1$ 
and $A>A^{c}(\gamma)$ is satisfied. Here the fact that there are at most three interior steady states plays a crucial role. In particular, when there are more than three interior steady states then the symmetric steady state can be locally stable but the divergence in the world economy can still occur. However, when the number of interior steady states is at most three then the local and global instability becomes equivalent.

\section{Endnotes}

aAmong these countries are: Argentina, Brazil, Bulgaria, Chile, Costa Rica, Georgia, Guatemala, Guyana, Latvia, Madagascar, Poland, Romania, Thailand, and others.

${ }^{\mathrm{b}}$ Recent scientific debate on land speculation (or land grabbing) can be found in a special issue of Journal of Peasant Studies published in 2011 (Vol. 38, issue 2).

cAccording to FNP Institute, an agribusiness consulting firm in Sao Paulo, in 2007 alone, farmland prices jumped by $16 \%$ in Brazil, by $31 \%$ in Poland, and by $15 \%$ in the Midwestern United States.

${ }^{\mathrm{d}}$ Two key assumptions behind this result is the diminishing returns technology and low income elasticity of agricultural demand.

${ }^{\text {e}}$ For details about the standard neoclassical overlapping generations model see Azariadis (2).

${ }^{\mathrm{f}}$ Capital can be interpreted broadly to include human capital, physical capital, or any other capital good used in production.

gMatsuyama (12) analyses the effect of agricultural productivity on economic growth and shows that high agricultural productivity is a precondition for high economic growth in case of autarky, while high agricultural productivity can become a barrier for economic growth in case of free trade. This is so because, in case of autarky, rising agricultural productivity makes it possible to free labor force from the agricultural sector. However, in the case of free trade, high agricultural productivity causes the specialization in the agricultural sector and leads to de-industrialization. In order to separate this feedback mechanism from the one considered in this paper, we assume that the land is the only factor for agricultural commodity production.

h Properties of $f$ and $u$ imply the existence and uniqueness of $x_{i t}$ which solves (2).

${ }^{i}$ See Lemma 1 in the Appendix.

jSince $k \mapsto \Psi(k)$ and $A \mapsto U(A)$ are both decreasing functions it follows that $A \mapsto$ $K^{*}(A)$, where $k=K^{*}(A)$ solves of $\Psi(k)=U(A)$, is a strictly increasing function.

${ }^{\mathrm{k}}$ Ranking of steady state welfare across countries coincides with the ranking of steady state capital because $A \mapsto K^{*}(A)$ and $A \mapsto \ln \left(f\left(K^{*}(A)\right)-K^{*}(A)\right)+u(A)$ are both strictly increasing functions.

${ }^{1}$ This result is consistent with Matsuyama (12). Engel's law plays a crucial role for this result. If income elasticity is unity, then the steady state capital is independent from productivity in the agricultural sector. If income elasticity is more than one, and so agricultural commodity is a luxury good, then a rise in agricultural productivity decreases the steady state capital.

${ }^{m}$ It is assumed that the young agents cannot invest in capital abroad. This assumption can be easily justified if one interprets capital as human or public capital.

${ }^{\mathrm{n}}$ As above, ranking of steady state welfare coincides with the ranking of steady state capital because $A \mapsto \ln \left(f\left(K^{*}(A)\right)-K^{*}(A)\right)+u(A)$ is a strictly increasing function.

${ }^{\mathrm{o}}$ It is clear that $(0,0)$ is a corner steady state of the economy. 


\section{Competing interests}

The author declares that he has no competing interest.

\section{Acknowledgements}

This paper was partly written at the European Commission, Directorate-General for Economic and Financial Affairs, where I was a Visiting Fellow in April 2010. I would like to thank Peter Grasmann, Heikki Oksanen, and two anonymous referees for their helpful comments and suggestions.

Received: 25 August 2012 Accepted: 18 March 2013

Published: 15 May 2013

\section{References}

1. Allen TJ: Global Land Grab. In These Times 2011:1-2. http://inthesetimes.com/article/11784/global_land_grab/.

2. Azariadis C: Intertemporal macroeconomics. London: Blackwell; 1993.

3. Borras M, Hall R, Scoones I, White B, Wolford W: Towards a better understanding of global land grabbing: an editorial introduction. $J$ Peasant Stud 2011, 38:209-216.

4. Chirinko RS: $\sigma$ : The long and short of it. J Macroeconomics 2008, 30:671-686.

5. Cotula L, Vermeulen S, Leonard R, Keeley J: Land grab or development opportunity? Agricultural investments and international land Delas in Africa, International institute for environment and development (IIED)/food and agriculture organization of the United Nations (FAO)/international fund for agricultural development (IFAD). London/Rome; 2009. http://www.fao.org/docrep/011/ak241e/ak241e00.htm.

6. Crafts N: Income elasticities of demand and the release of labour by agriculture during the British industrial revolution. J Eur Econ Hist 1980, 9:153-168.

7. Gollin D: Getting income shares right. J Pol Econ 2002, 110:458-74

8. Guckenheimer J, Holmes P: Nonlinear oscillations, dynamical systems, and bifurcations of vector fields. New York: Springer; 1983.

9. Hartman P: Ordinary differential equations. New York: Wiley; 1964.

10. Klump R, McAdam P, Willman A: Factor substitution and factor augmenting technical progress in the United States: a normalized supply-side system approach. Rev Econ Stat 2007, 89:183-192.

11. Li TM: Centering labor in the land grab debate. J Peasant Stud 2011, 38:281-298.

12. Matsuyama K: Agricultural productivity, comparative advantage, and economic growth. J Econ Theory 1992, 58:317-334.

13. Nierenberg D, Pollack B: Innovations in access to land: land grab or agricultural investment? Huffington Post 2010:1. http://www.huffingtonpost.com/danielle-nierenberg/innovations-in-access-to_b_671773.html.

14. Piyabha K, Rebelo S, Xie D: Beyond balanced growth. Rev Econ Stud 2001, 68:869-882.

15. Vidal J: Fears for the world's Poor countries as the rich grab land to grow food. Guardian 2009:1. http://www. guardian.co.uk/environment/2009/jul/03/land-grabbing-food-environment.

16. Von Braun J, Meinzen-Dick R: Land grabbing by foreign investors in Developing countries: Risks and opportunities. Policy brief: International food policy research institute; 2009. http://www.ffpri.org/publication/land-grabbing-foreigninvestors-developing-countries.

17. World Bank: World Development Report 2008: Agriculture for development. Washington, DC; 2008. pp 1-355. http:// siteresources.worldbank.org/INTWDR2008/Resources/WDR_00_book.pdf.

doi:10.1186/2193-7532-1-2

Cite this article as: Vachadze: Capital accumulation with and without land market liberalization: beyond the "WinWin" situation. Agricultural and Food Economics 2013 1:2.

\section{Submit your manuscript to a SpringerOpen ${ }^{\circ}$ journal and benefit from:}

- Convenient online submission

- Rigorous peer review

- Immediate publication on acceptance

- Open access: articles freely available online

- High visibility within the field

- Retaining the copyright to your article

Submit your next manuscript at $>$ springeropen.com 